\title{
Nebulised hypertonic saline (3\%) among children with mild to moderately severe bronchiolitis - a double blind randomized controlled trial
}

Aayush Khanal ${ }^{1 *}$, Arun Sharma ${ }^{1}$, Srijana Basnet ${ }^{1}$, Pushpa Raj Sharma ${ }^{1,2}$ and Fakir Chandra Gami ${ }^{1}$

\begin{abstract}
Background: To Assess the efficacy of nebulised hypertonic saline (HS) (3 \%) among children with mild to moderately severe bronchiolitis.

Methods: Infants aged 6 weeks to 24 months, with a first episode of wheezing and Clinical Severity scores (Arch Dis Child 67:289-93, 1992) between 1 and 8, were enrolled over 4 months duration. Those with severe disease, co-morbidities, prior wheezing, recent bronchodilator and steroid use were excluded. Patients were randomized in a double-blind fashion, to receive two doses of nebulized $3 \% \mathrm{HS}$ (Group 1) or $0.9 \%$ normal saline (Group 2) with $1.5 \mathrm{mg}$ of L-Epineprine, delivered 30 min apart. Parents were contacted at $24 \mathrm{~h}$ and 7 days. The principal outcome measure was the mean change in clinical severity score at the end of $2 \mathrm{~h}$ of observation.

Results: A total of 100 infants (mean age 9.6 months, range 2-23 months; $61 \%$ males) were enrolled. Patients in both groups had mild to moderately severe disease at presentation. On an intention-to-treat basis, the infants in the HS group had a significant reduction $(3.57 \pm 1.41)$ in the mean clinical severity score compared to those in the NS group (2.26 \pm 1.15$)$; $[p<0.001$; Cl: $0.78-1.82]$. More children in the HS group $(n=35 / 50 ; 70.0 \%)$ were eligible for ER/OPD discharge at the end of $2 \mathrm{~h}$ than those in the NS group ( $n=15 / 50 ; 30 \% ; p<0.001)$, and less likely to need a hospital re-visit $(n=5 / 50 ; 10.0 \%)$ in the next $24 \mathrm{~h}$ as compared to the NS group $(n=15 / 50,30.0 \% ; p<0.001)$. The treatment was well tolerated, with no adverse effects.
\end{abstract}

Conclusions: Nebulized $3 \%$ HS is effective, safe and superior to normal saline for outpatient management of infants with mild to moderately severe viral bronchiolitis in improving Clinical Severity Scores, facilitating early Out-Patient Department discharge and preventing hospital re-visits and admissions in the $24 \mathrm{~h}$ of presentation.

Trial registration: Clinicaltrials.gov NCTID012766821. Registered on January 12, 2011.

Keywords: Bronchiolitis, Clinical severity score, Epinephrine, Hypertonic saline

\section{Background}

Bronchiolitis is a common, occasionally severe viral infection of the lower respiratory tract responsible for significant morbidity and mortality in children under two years of age [1]. According to World Health Organization bulletin, an estimated 150 million new cases of clinical pneumonia (principally Pneumonia and Bronchiolitis) occur annually

\footnotetext{
* Correspondence: aayush_khanal@iom.edu.np; aayush_khanal@yahoo.com 'Department of Pediatrics, Tribhuvan University Teaching Hospital, Institute of Medicine, Maharajgunj-44600, P.O. Box 1524, Kathmandu, Nepal
} Full list of author information is available at the end of the article
[2]; 11-20 million among them requiring hospital admission. Worldwide, $95 \%$ of all cases occur in developing countries [2]. Epidemiologic data show that RSV accounts for about $65 \%$ of hospitalizations due to Bronchiolitis [3].

Multiple studies [4-7] have documented variation in diagnostic testing, treatment modalities practiced and their outcomes in Bronchiolitis suggesting a lack of consensus for this common disorder. Likewise, despite the frequency of this condition, there is no unanimously accepted evidence driven treatment approach [8, 9]. Besides supplemental oxygen, fluids and supportive care, treatment

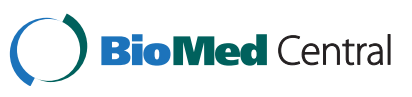

(c) 2015 Khanal et al. Open Access This article is distributed under the terms of the Creative Commons Attribution 4.0 International License (http://creativecommons.org/licenses/by/4.0/), which permits unrestricted use, distribution, and reproduction in any medium, provided you give appropriate credit to the original author(s) and the source, provide a link to the Creative Commons license, and indicate if changes were made. The Creative Commons Public Domain Dedication waiver (http://creativecommons.org/publicdomain/zero/1.0/) applies to the data made available in this article, unless otherwise stated. 
options include, bronchodilators, epinephrine and corticosteroids [9]. Hypertonic saline (3\%) is a new agent that has been found to be promising in recent studies [10-20]. The proposed mechanism are by improving mucus rheology, reducing airway wall edema and causing sputum induction and cough [12]. A recent meta-analysis [10] also showed a consistent improvement in clinical severity scores and suggested HS may also decrease the length of hospital stay in Bronchiolitis. However, multiple other studies [8, 13, 21-25] have shown equivocal results with little or no clinical benefits with the use of hypertonic saline (3, 6 or $7 \%)$. Similary, there is a paucity of data on comparison of important outcomes like readiness for discharge, need for repeat hospital visits and hospitalization rates, which are important reflectors of morbidity and economic burden [10]. In the paucity of rigorously controlled studies in developing countries using $3 \% \mathrm{HS}$, lack of a consensus regarding management of bronchiolitis in our practice and an opportunity to improve care for this common disorder this study was conducted to assess the therapeutic efficacy of $3 \% \mathrm{HS}$. We tried to study primarily the improvement in CS scores but also looked at parameters like readiness for discharge, need for hospital revisit rates and hospitalization which would reflect the morbidity and financial burden of disease.

\section{Methods}

\section{Trial design}

This study was a prospective, interventional, doubleblind randomized controlled trial.

\section{Ethical clearance}

A written informed consent was obtained from the primary caretaker of the patients prior to the enrollment. The study was approved by the Department of Research, Institutional Review Board and Ethics Committee of Tribhuvan University Teaching Hospital.

\section{Study participants}

Subjects were recruited from previously healthy children visiting the Emergency Room (ER) and Out-Patient Department (OPD) of Kanti Children Hospital with the following inclusion criteria:

1. Age between 6 weeks and 2 years
2. First Episode of Wheezing

3. Meets Clinical Definition of Bronchiolitis

4. Clinical severity (CS) scores (Wang et al [26]) between 1 and 9 (Table 1).

Bronchiolitis was clinically defined as per the AAP consensus guidelines [4, 27] as the first episode of acute wheezing in children less than two years of age, starting as a viral upper respiratory infection (coryza, cough or fever).

\section{Exclusion criteria}

1. Any underlying disease (e.g., cystic fibrosis, bronchopulmonary dysplasia and cardiac or renal disease),

2. Prior history of wheezing,

3. Diagnosed case of asthma,

4. Oxygen saturation $(\mathrm{SpO} 2)<85 \%$ on room air,

5. CS score $>9$,

6. Progressive respiratory distress requiring mechanical ventilation,

7. Previous treatment with bronchodilators within last 4 $\mathrm{h}$, and

8. Any steroid therapy within $48 \mathrm{~h}$

\section{Study setting}

The study was carried out in the ER, Observation room (OR) and OPD. Recruitment occurred at the peak of bronchiolitis season in between January 15th to April 15th for duration of 4 months.

\section{Patient assessment}

Patient enrollment occurred on weekdays between 08.00 and $17.00 \mathrm{~h}$. The investigator assessed the children for eligibility and assigned a clinical severity (CS) score described by Wang et al. [26] (Table 1). Data were collected using standardized forms to document pertinent history and physical exam. Each children's weight, temperature, respiratory rate, $\mathrm{SpO} 2$ in room air (determined by pulse oximeter, Siemens), heart rate, CS Score and hydration status were recorded. The children were stabilized with antipyretics if necessary (temperature $>38.3 \% \mathrm{C}$ ) and/or nasal suction if the nose was blocked. Supplemental oxygen by face mask was provided to maintain $\mathrm{SpO} 2>90 \%$.

Table 1 Wang et al. clinical severity score

\begin{tabular}{|c|c|c|c|c|}
\hline \multirow[t]{2}{*}{ Variables } & \multirow[b]{2}{*}{0} & \multicolumn{3}{|l|}{ Score } \\
\hline & & 1 & 2 & 3 \\
\hline $\mathrm{RR}$ & $<30$ & $31-45$ & $46-60$ & $>60$ \\
\hline Wheezing & None & $\begin{array}{l}\text { Terminal expiration/only } \\
\text { with stethoscope }\end{array}$ & $\begin{array}{l}\text { Entire expiration or audible on } \\
\text { exp. without stethoscope }\end{array}$ & $\begin{array}{l}\text { Inspiration and expiration } \\
\text { without stethoscope }\end{array}$ \\
\hline Retraction & None & Intercostals & Tracheo-sternal & Severe with nasal flaring \\
\hline General condition & Normal & & & Irritable, lethargic, poor feeding \\
\hline
\end{tabular}


Patients determined to be in life threatening condition were immediately managed for same and were not further considered for study.

\section{Interventions}

The study drugs were prepared by a pharmacist, administered by an ER/OPD nurse and compliance with medication administration was assured by the investigator's direct observation of each nebulization.

All eligible patients were randomly assigned to one of the two groups:

1. Group $1(n=50)$ received inhalation of L-Epinephrine $1.5 \mathrm{mg}$, diluted to $4 \mathrm{ml}$ with $3 \%$ Hypertonic 1 Saline (HS) solution;

2. Group $2(n=50)$ received inhalation of L-Epinephrine, $1.5 \mathrm{mg}$, diluted to $4 \mathrm{ml}$ with $0.9 \%$ Normal Saline solution.

The study drug was administered at 0 and 30 min by a Jet nebulizer using a face mask. The investigator assessed the children's general condition and recorded the CS score, $\mathrm{SpO} 2, \mathrm{RR}$ and $\mathrm{HR}$ prior to each drug administration and at 30, 60 and $120 \mathrm{~min}$ after the first nebulization.

The study design is shown in Fig. 1.

Adverse events were defined as heart rate $>200$, tremor and worsening clinical status. Patients were excluded from the study if the two courses of nebulisation was not delivered, the drug delivery was delayed by 10 min or more (protocol deviation) or if clinical deterioration mandated escalation of therapy and/or support.

The investigator contacted the parents via telephone $24 \mathrm{~h}$ after their ED/OPD discharge to determine the need for any unscheduled hospital visit and hospitalization within the next $24 \mathrm{~h}$ of OPD/ ER visit: their readmission (relapse) rate. The register at the ER/OR was checked daily for any unscheduled visits by the caretakers. They were also contacted at the end of 1 week in order to record any unscheduled medical visits, missed working days of caregivers and persistence of cough. Patients were labeled as Lost-toFollow up if there was failure to communicate for 3 consecutive attempts for 2 consecutive days at their 7 th and 8th day of initial presentation to the OPD/ER.

\section{Primary outcome}

Compare the mean change in Clinical Severity score among patients with bronchiolitis treated with either L-Epinephrine- $3 \%$ Hypertonic saline or L-Epinephrine$0.9 \%$ saline.

\section{Secondary outcomes}

a. Assess the improvements in $\mathrm{SpO} 2$, respiratory rate and heart rate in both intervention groups.

b. Compare the discharge readiness and readmission rates in both intervention groups at the end of $2 \mathrm{~h}$ of observation and within $24 \mathrm{~h}$ following discharge respectively.

c. Describe the socioeconomic burden of illness.

\section{Sample size}

Sample size was determined by the following formula:

$$
\mathbf{N}=\left[(\mathbf{z} \mathbf{1}+\mathbf{z} 2)^{2}\left(\mathbf{O ́}^{2}+\mathrm{O}^{2} \mathbf{2}^{2}\right)\right] /(\hat{\mathbf{u}} \mathbf{1}-\hat{\mathbf{u}} \mathbf{2})^{2} \text {. }
$$

- N: Sample Size

- z1: The confidence level, for $p$ value: 0.05, z1: 1.96 .

- z2: 0.84 for Power of $80 \%$

1.28 for Power of $90 \%$

1.64 for Power of $95 \%$

- O1: Standard Deviation of the Outcome Variable (Clinical Severity Score) in the $1^{\text {st }}$ intervention group (HS)

- Ó2: Standard deviation of the outcome variable (Clinical severity score) in the $2^{\text {nd }}$ intervention group (NS)

- Û 1: Mean change in clinical severity score among $1^{\text {st }}$ intervention group (HS)

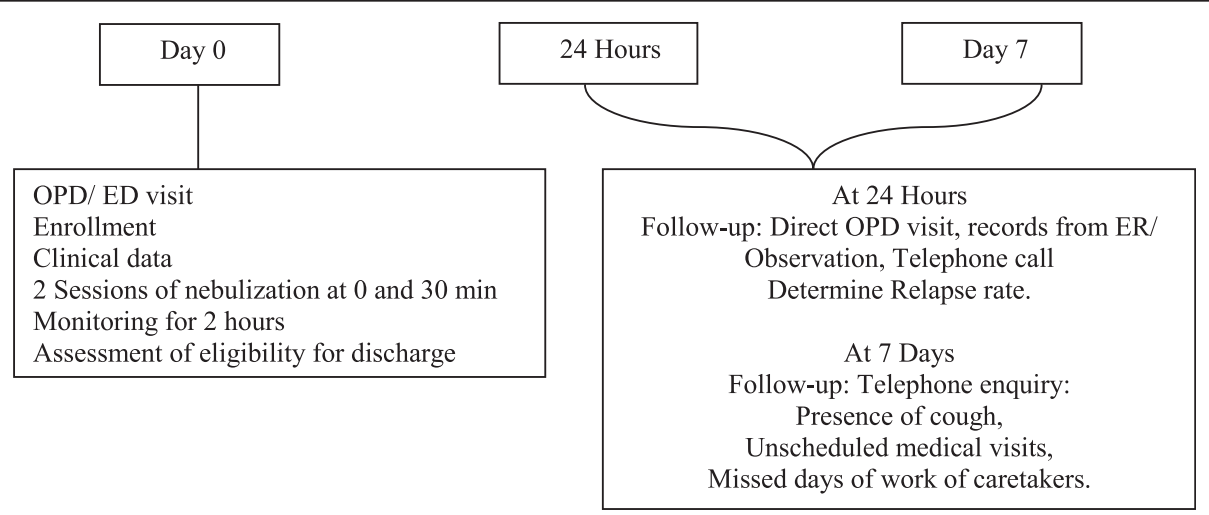

Fig. 1 The study design 


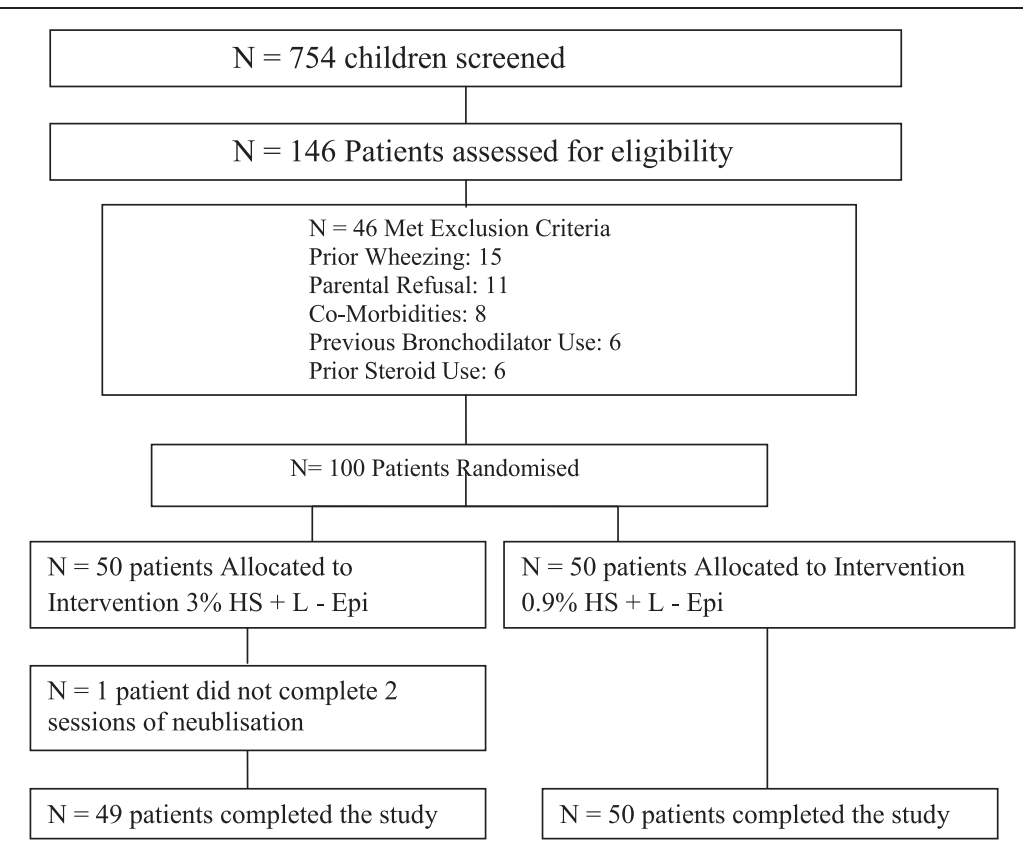

Fig. 2 The trial profile

- $\hat{U}$ 2: Mean change in clinical severity score among $2^{\text {nd }}$ intervention group (NS)

- Allowing a Type1 error of $5 \%$ ( $\alpha$ : 0.05), z1 score: 1.96.

- For a Power of $95 \%, \mathrm{z} 2=1.64$.

The standard deviation of the change in CS score is derived from previous studies [8] and taken as 1.3. We proposed that a difference of 1 point in the CS score between the two intervention groups will be considered clinically significant. To detect this mean difference of 1 unit in the CS score, with a power of $95 \%$, a sample size of 44 in each intervention group was required. This required a total of 88 patients to be enrolled in the study. Considering the drop out/lost to follow up to be approximately $10 \%, 100$ patients were enrolled, allowing 50 in each group.

\section{Randomization}

\section{Sequence generation}

A Random Allocation Software [28] generated by computer, identified patients by a triple digit mixed numeric code, was used by the study coordinator to allocate patients to treatment groups, and he was the only person with access to the randomization.

\section{Type of randomization}

Block Randomization method was used to stratify patients into blocks of 10 each, each comprising of 10 patients.

\section{Allocation concealment}

After preparation, the study solutions were labeled with the codes and wrapped in an envelope bearing the

Table 2 Baseline characteristics of 2 groups

\begin{tabular}{|c|c|c|c|}
\hline \multirow[t]{2}{*}{ Characteristics; mean(SD); (range) } & Intervention & Intervention & \multirow[t]{2}{*}{$p$ value } \\
\hline & L-Epi + $3 \%$ HS $(n=50)$ & L-Epi $+0.9 \%$ NS $(n=50)$ & \\
\hline Age (months), mean (SD); (range) & $9.82(5.06) ;(2-23)$ & $9.51(4.28) ;(3-22)$ & 0.74 \\
\hline Males, n(\%) & $27(54.0 \%)$ & $21(42.0 \%)$ & 0.40 \\
\hline Duration of illness (days), Mean \pm SD & $3.43 \pm 1.02$ & $3.33 \pm 0.96$ & 0.64 \\
\hline Mean (SD) respiratory rate (range) & $49.1(2.5)(46-60)$ & $49.0(2.0)(46-58)$ & 0.79 \\
\hline Mean (SD) heart rate (range) & $148.7(7.5)(132-168)$ & $149.7(7.1)(132-166)$ & 0.49 \\
\hline Mean (SD) Spo2 (range) & $93.4(0.8)(90-95)$ & $93.5(0.7)(90-94)$ & 0.69 \\
\hline Mean (SD) clinical severity score (range) & $5.3(1.6)(3-9)$ & $5.2(1.1)(3-9)$ & 0.57 \\
\hline Mean temperature $(\mathrm{SD})$ temperature $\left({ }^{*} \mathrm{C}\right)$ (range) & $37.2(-17.4)(36.7-38.0)$ & $37.3(-17.4)(36.6-38.0)$ & 0.82 \\
\hline Urine specific gravity & 1016 & 1022 & 0.001 \\
\hline ER enrollment, $\mathrm{n}(\%)$ & $2(4 \%)$ & $2(4 \%)$ & 1.00 \\
\hline
\end{tabular}


Table 3 Distribution of risk factors proposed to contribute to prolonged disease course and, or severity in both intervention groups

\begin{tabular}{|c|c|c|c|}
\hline Variables & $\begin{array}{l}3 \% \text { HS + L-Epi } \\
(n=50)\end{array}$ & $\begin{array}{l}0.9 \% \text { NS + L-Epi } \\
(n=50)\end{array}$ & $p$-value \\
\hline $\begin{array}{l}\text { Family history of asthma, } \\
\mathrm{n}(\%)\end{array}$ & $4(8.0)$ & $5(10.0)$ & 1.00 \\
\hline Parental smoking, n (\%) & $30(60.0)$ & $21(42.0)$ & 0.05 \\
\hline Exposure to biofuels, n (\%) & $14(28.0)$ & $8(16.0)$ & 0.11 \\
\hline Breastfeeding status, n (\%) & $48(96.0)$ & $48(96.0)$ & 0.75 \\
\hline Prematurity, n (\%) & $3(6.0)$ & $2(4.0)$ & 0.50 \\
\hline Atopic history, n (\%) & $7(14.0)$ & $3(6.0)$ & 0.15 \\
\hline
\end{tabular}

respective codes. Study solutions were identical in appearance and odor. Their identity was blinded to all participants, care providers, and investigators and outcome assessor.

\section{Implementation}

Randomization was done by the study coordinator (not involved in the study), who was the only person to have access to the codes. The codes were a mixed 3 digit numeric code. The study solutions prepared by a pharmacist (not involved in the study) were stored in the non-freezer compartment $(2-8 * \mathrm{C})$ of the refrigerator and discarded if not used within $72 \mathrm{~h}$ of preparation. The investigator assessed the patients and allocated the treatment modalities to each one of them himself.

\section{Blinding}

The study was a Double Blind Randomized Controlled Trial with the investigator, the participants, the nurses who delivered the drug being blinded to the therapeutic option.

\section{Statistical methods}

Statistical analysis was performed using SPSS for Windows, Release 16.0 (SPSS Inc., Chicago, IL). Dichotomous events were analyzed by using the Chi-Square test. Continuous variables were compared by Student $t$-test. Statistical significance was defined as $p$-value $<0.05$. This trial has been reported in accordance to the Consolidated Standards of Reporting Trials (CONSORT, 2010) guidelines [29].

\section{Results and discussion}

A total of 754 children were screened and 146 previously well children were assessed for eligibility in the study periodas shown in Fig. 2. Forty-Six children were

Table 4 Mean $\left( \pm\right.$ SD) for CS Score, respiratory rate, heart rate and $\mathrm{SpO}_{2}$ for patients in each group at 0,30,60 and 120 min of assessment

\begin{tabular}{|c|c|c|c|c|}
\hline & $\begin{array}{l}\text { Intervention } \\
0.9 \% \text { NS + L-Epi } \\
(n=50)\end{array}$ & $\begin{array}{l}\text { Intervention } \\
3 \% \text { HS + L-Epi } \\
(n=50)\end{array}$ & $p$ value & $\begin{array}{l}95 \% \text { confidence interval lower } \\
\text { limits - upper limits (mean) }\end{array}$ \\
\hline \multicolumn{5}{|c|}{ CS score, $n$, Mean \pm S.D; range } \\
\hline $0 \mathrm{~min}$ & $5.2 \pm 1.1(3-9)$ & $5.3 \pm 1.6 ;(3-9)$ & 0.57 & $-0.73 ; 0.41(-0.15)$ \\
\hline $30 \mathrm{~min}$ & $4.9 \pm 1.1 ;(3-8)$ & $4.3 \pm 2.0 ;(2-8)$ & 0.10 & $-0.11 ; 1.21(0.55)$ \\
\hline $60 \mathrm{~min}$ & $3.2 \pm 1.0 ;(1-6)$ & $2.2 \pm 1.2 ;(1-7)$ & 0.001 & $0.52 ; 1.43(0.97)$ \\
\hline $120 \mathrm{~min}$ & $2.9 \pm 0.8 ;(1-5)$ & $1.7 \pm 0.9 ;(1-7)$ & 0.001 & $0.77 ; 1.52(1.14)$ \\
\hline \multicolumn{5}{|c|}{ Respiratory rate, breaths/minute, Mean \pm S.D; range } \\
\hline $0 \mathrm{~min}$ & $49.0 \pm 2.0 ;(46-58)$ & $49.1 \pm 2.5 ;(46-60)$ & 0.79 & $-1.01 ; 0.81(-0.12)$ \\
\hline $30 \mathrm{~min}$ & $47.4 \pm 1.7 ;(46-54)$ & $46.6 \pm 2.1 ;(42-56)$ & 0.04 & $0.04 ; 1.61(0.81)$ \\
\hline $60 \mathrm{~min}$ & $45.3 \pm 1.4 ;(42-50)$ & $43.5 \pm 2.0 ;(40-52)$ & 0.001 & $1.13 ; 2.57(1.85)$ \\
\hline $120 \mathrm{~min}$ & $43.6 \pm 2.6 ;(40-48)$ & $40.7 \pm 2.0 ;(38-49)$ & 0.001 & $1.97 ; 3.86(2.91)$ \\
\hline \multicolumn{5}{|c|}{ Oxygen saturation, $\%$, Mean \pm S.D; range } \\
\hline $0 \mathrm{~min}$ & $93.5 \pm 0.7 ;(90-94)$ & $93.4 \pm 0.8(90-95)$ & 0.69 & $-0.22 ; 0.40(0.09)$ \\
\hline $30 \mathrm{~min}$ & $93.8 \pm 0.8 ;(91-96)$ & $94.2 \pm 1.2 ;(90-96)$ & 0.07 & $-0.79 ; 0.06(-0.36)$ \\
\hline $60 \mathrm{~min}$ & $94.9 \pm 0.9 ;(92-97)$ & $95.8 \pm 1.1 ;(92-98)$ & 0.001 & $-1.34 ;-0.48(-0.97)$ \\
\hline $120 \mathrm{~min}$ & $95.6 \pm 1.0 ;(93-98)$ & $97.0 \pm 1.0 ;(93-99)$ & 0.001 & $-1.77 ;-0.91(-1.14)$ \\
\hline \multicolumn{5}{|c|}{ Heart rate, beats/minute, Mean \pm S.D; range } \\
\hline $0 \mathrm{~min}$ & $149.7 \pm 7.1 ;(132-166)$ & $148.7 \pm 7.5 ;(132-168)$ & 0.49 & $-1.94 ; 3.98(0.80)$ \\
\hline $30 \mathrm{~min}$ & $149.7 \pm 7.9 ;(130-164)$ & $147.1 \pm 9.1 ;(130-164)$ & 0.13 & $-0.93 ; 6.04(2.91)$ \\
\hline $60 \mathrm{~min}$ & $145.2 \pm 6.4 ;(130-156)$ & $142.6 \pm 7.2 ;(126-156)$ & 0.06 & $-0.20 ; 5.30(2.55)$ \\
\hline $120 \mathrm{~min}$ & $141.8 \pm 5.8 ;(126-154)$ & $138.3 \pm 6.6 ;(124-152)$ & 0.006 & $1.02 ; 6.03(3.53)$ \\
\hline
\end{tabular}


excluded and 99 patients completed the study. Data was analyzed on an intention to treat basis.

No significant differences were noted between the study groups with respect to baseline characteristics $(p>0.05)$ and risk factors for severity as shown in Table 2 and Table 3 respectively. Patients in both groups had moderately severe bronchiolitis with mean CS score above 5 . There is gradual improvement in CS score with time in both the groups and the effect seemed to be more pronounced after the second session of nebulisation at 60 min. Patients who received nebulised HS had more significant improvement in the baseline CS scores (Group 1, a change of $3.57 \pm 1.41$; Group 2 , a change of $2.26 \pm 1.15$; $p<0.01$ ) at the end of $2 \mathrm{~h}$ of therapy as shown in Table 5 . There was also significant difference in the mean change in CS scores, HR, RR and SpO2 between the two groups at the start of treatment and at the end of $2 \mathrm{~h}$ of therapy $(p<0.001)$ as shown in Table 4 and Table 5. More infants who received HS were eligible for discharge at the end of $2 \mathrm{~h}$ as compared to NS [Group 1, $n=35$ (71.0\%); Group 2, $n=15(30.0 \%) ; p<0.001]$ as shown in Table 6 .

In addition, in our trial the need for repeat medical visits and hospital admission within the next $24 \mathrm{~h}$ of initial hospital visit (Relapse rate) was $20 \%$, which was significantly lesser in the babies who received HS compared to those who received NS [Group 1, $n=5(10.0 \%)$; Group 2, $n=15$ (30.0\%); $p<0.001$ ] as shown in Table 6. During the subsequent week, 78 out of 100 patients (Group 1, $n=37$; Group 2, $n=41$ ) were accessible. As shown in Table 7, a large number of patients in both groups had persistent cough at the end of 1 week (Group 1, $n=31$; Group 2, $n=37 ; p=0.45$ ). Eighteen patients from HS Group and 23 patients from NS Group had at least 1 unscheduled medical visit within 1 week $(p=0.58$; overall revisit rates $41 / 88 ; 46.5 \%)$ and 3 parents from HS Group and 10 patients from NS Group reported at missing least 1 day of work ( $p=0.17$; total missed days of work 10 / 77; $12.9 \%)$. No adverse events occurred in either treatment groups. No children were withdrawn from the trial due to side effects or clinical deterioration.

Table 5 Clinical outcomes in the two intervention groups at the end of $2 \mathrm{~h}$ of treatment

\begin{tabular}{|c|c|c|c|c|}
\hline $\begin{array}{l}\text { Variables } \\
\text { (Mean } \pm \text { SD) }\end{array}$ & $\begin{array}{l}\text { Intervention } \\
3 \% \mathrm{HS}+\text { L-Epi }\end{array}$ & $\begin{array}{l}\text { Intervention } \\
0.9 \% \text { NS+ L-Epi }\end{array}$ & $p$ value & $\begin{array}{l}95 \% \text { confidence } \\
\text { interval (mean) }\end{array}$ \\
\hline $\begin{array}{l}\text { Change in } \\
\text { CS Score }\end{array}$ & $3.57 \pm 1.41$ & $2.26 \pm 1.15$ & 0.001 & $0.78 ; 1.82$ (1.30) \\
\hline $\begin{array}{l}\text { Change } \\
\text { in HR }\end{array}$ & $10.38 \pm 4.54$ & $7.87 \pm 3.63$ & 0.003 & $0.86 ; 4.16(2.50)$ \\
\hline $\begin{array}{l}\text { Change } \\
\text { in } R R\end{array}$ & $8.44 \pm 2.15$ & $5.40 \pm 2.57$ & 0.001 & $2.08 ; 3.99$ (3.04) \\
\hline $\begin{array}{l}\text { Change } \\
\text { in } \mathrm{SpO}_{2}\end{array}$ & $3.53 \pm 0.84$ & $2.12 \pm 0.80$ & 0.001 & $1.07 ; 1.73(1.30)$ \\
\hline
\end{tabular}

Table 6 Secondary outcomes

\begin{tabular}{llll}
\hline & $\begin{array}{l}\text { Intervention 3 \% HS } \\
+\mathrm{L}-\text {-Epi }\end{array}$ & $\begin{array}{l}\text { Intervention } 0.9 \% \\
+\mathrm{L}-\text {-Epi }\end{array}$ & $p$ value \\
\hline $\begin{array}{l}\text { Met criteria for } \\
\text { ER/OPD discharge }\end{array}$ & $35(70.0 \%)$ & $15(30.0 \%)$ & 0.001 \\
after 120 mins, $\mathrm{n}(\%)$ & & & \\
Relapse rate, $\mathrm{n}(\%)$ & $5(10.0 \%)$ & $15(30.0 \%)$ & 0.02 \\
Need for intensive care & $1(2.0 \%)$ & $1(2.0 \%)$ & 1.00 \\
\hline
\end{tabular}

Ours is one of the few studies conducted in SouthEast Asia with a rigorously controlled design that has not only tried to look at the role of hypertonic saline in improving the CS scores but also studied its impact on early discharge eligibility and hospital revisit rates. In both treatment groups, change in CS was greater than 2 scores suggesting that both treatment combinations were effective. More infants with bronchiolitis were eligible for early discharge and less likely to need any hospital re-visit within the next $24 \mathrm{~h}(p<0.001)$. This outcome seems to be particularly relevant in planning resource allocation and staffing in treatment of this common condition.

Similar findings were reported in a recent Cochrane review [10] by Zhang et al., where a total of 560 patients treated with nebulised $3 \%$ saline had a significantly shorter mean length of hospital stay and significantly lower post-inhalation clinical score than the $0.9 \%$ saline group in the first three days of treatment $(p<0.001)$. The effects of improving clinical score were observed in both outpatients and inpatients.

On the Contrary, in another double blind RCT, Wu et al. in 2014 [24] assessed the role of nebulised $3 \%$ HS on change in RDAI scores, admission rates and length of stay in Bronchiolitis. They concluded that HS given to children in the ED decreases hospital admissions but did not produce any significant difference in Respiratory Distress Assessment Instrument score or length of stay as compared to NS.

Likewise, Florin et al. [22] conducted a RCT in ER setting and found that at $1 \mathrm{~h}$ after the intervention, the

Table 7 Burden placed on caretakers due to bronchiolitis

\begin{tabular}{|c|c|c|c|}
\hline & $\begin{array}{l}\text { Intervention } 3 \% \\
\text { HS + L-Epi }\end{array}$ & $\begin{array}{l}\text { Intervention } 0.9 \% \\
\text { NS + L-Epi }\end{array}$ & $p$ value \\
\hline $\begin{array}{l}\text { Need for unscheduled } \\
\text { medical visits within } \\
1 \text { week, } n(\%)\end{array}$ & $18(36.0 \%)$ & $23(46.0 \%)$ & 0.58 \\
\hline Missed days of work & $3(6.0 \%)$ & 10 (20.0\%) & 0.17 \\
\hline $\begin{array}{l}\text { Persistence of cough } \\
\text { at the end of } 1 \text { week, } \\
n(\%)\end{array}$ & $31(62.0 \%)$ & 37 (74.0 \%) & 0.37 \\
\hline
\end{tabular}


HS group demonstrated significantly less improvement in the median RDAI Score compared with the NS group $(p<0.001)$ and hence concluded that nebulised $3 \%$ Saline was not effective in improving RDAI scores in the ER setting.

Previously, Sarrell et al. [19] had shown that substituting hypertonic saline for normal saline solution $(2 \mathrm{ml})$ in the inhalation mixture for delivering bronchodilator improved clinical scores and decreased hospitalization rates in ambulatory children. In hospitalized children with more severe bronchiolitis, nebulized $4 \mathrm{ml}$ hypertonic saline solution with or without epinephrine was found to be more effective treatment. In our study all infants recovered in both the groups, there was no treatment failure or significant adverse events following nebulisation, as previously reported by Ralston et al. [30].

Our study was well designed to minimize the common bias and limitations associated with research. Sampling bias was addressed by block randomization of patients. Blinding was maintained throughout the study period. A single observer's assessments nullified the chances of inter-observer variability. Despite these measures, some amount of bias and attrition is inevitable. We could not clarify the additional benefits of supportive care alone in infants with bronchiolitis since we didn't have a placebo arm. Although we considered important outcomes such as hospital revisit and admission rates, we did not assess the impact of therapy on the length of hospital stay. Our study population consisted mainly of infants who presented earlier, had mostly mild symptoms and experienced significant benefits. We are unsure, if similar benefits could be reproduced in infants with a more severe disease presentation. Although, we had strict inclusion and exclusion criteria, and identified potential risk factors for asthma, we might have included infants with first episode of asthma. RSV testing was unavailable and hence not done. We are also unsure if co-infection worsens the outlook in our infants.

Our study was conducted at the largest tertiary level pediatric referral centre of our country with over 1000 ER visits per month and more than 10,000 OPD visits per month with seasonal variation. Our sampled population characteristics were truly representative of the general population visiting Kanti Children's Hospital. Strict inclusion and exclusion criteria were used to minimize possible confounding effects of uncharacterized and evolving wheezing phenotypes. A well defined objective, previously validated scoring system was used to assess the clinical response. Our adequate sample size, and double blinded design minimizes the common bias and limitations associated with research. Since our study only consisted of mild to moderate patients with Bronchiolitis, results may need caution while extrapolating to infants with severe disease.

\section{Conclusion}

Nebulised $3 \%$ hypertonic saline in combination with epinephrine was effective in reducing the Clinical Severity scores, meeting the eligibility criteria for OPD/ER discharge and reducing the need for hospital admission among ambulatory children with bronchiolitis. We believe this simple, inexpensive, safe, and effective treatment intervention could minimize the morbidity of Bronchiolitis by generalizing its use in centers caring for pediatric patients. Similar study could be done in multicentric settings with a larger sample size, involving more severely affected patients, and with a placebo control design in order to confirm and extend our results.

\section{Abbreviations}

AAP: American Academy of Pediatrics; Cl: $95 \%$ confidence interval; CS: Clinical severity score; ER: Emergency room; HS: Hypertonic saline; OPD: Out-patient department; OR: Observation room; L-Epi: L-Epinephrine; Spo2: Oxygen saturation as measured by pulse oximeter; HR: Heart rate; RR: Respiratory rate.

\section{Competing interests}

The authors declare that they have no competing interests.

\section{Authors' contributions}

AK: Selected and designed the study, enrolled the patients and prepared the results. AS: Edited the Study Protcol including design, randomization and blinding techniques, made amendments where required, Performed critical Appraisal. SB: Revision of the Study Protocol and Performed Statistical analysis and Critical Appraisal. PS: Reviewed and Edited the Study Protocol and performed Critical Appraisal. FG: Reviewed and Edited the Study Protocol and performed Critical appraisal. All authors read and approved the final manuscript.

\section{Author details}

'Department of Pediatrics, Tribhuvan University Teaching Hospital, Institute of Medicine, Maharajgunj-44600, P.O. Box 1524, Kathmandu, Nepal.

${ }^{2}$ Kathmandu Medical College Teaching Hospital, Sinamangal, Kathmandu, Nepal.

Received: 9 September 2014 Accepted: 26 August 2015

Published online: 10 September 2015

\section{References}

1. Chaudhary K, Sinert R. Is nebulized hypertonic saline solution an effective treatment for bronchiolitis in infants? Ann Emerg Med. 2010;55:120-2.

2. Igor R, Tomaskovic L, Boschi-Pinto C, Campbell H. Global estimate of the incidence of clinical pneumonia among children under 5 years of age. Bull World Health Organ. 2004;82:895-903.

3. Weber MW, Mulholland EK, Greenwood BM. Respiratory syncytial virus infection in tropical and developing countries. Trop Med Int Health. 1998;3(4):268-80.

4. Zorc JJ, Hall CB. Bronchiolitis: recent evidence on diagnosis and management. Pediatrics. 2010;125:342-9.

5. Behrendt CE, Decker MD, Burch DJ, Watson PH. International variation in the management of infants hospitalized with respiratory syncytial virus. International RSV Study Group. Eur J Pediatr. 1998;157(3):215-20.

6. Christakis DA, Cowan CA, Garrison MM, Molteni R, Marcuse E, Zerr DM. Variation in inpatient diagnostic testing and management of bronchiolitis. Pediatrics. 2005;115(4):878-84.

7. Willson DF, Horn SD, Hendley JO, Smout R, Gassaway J. Effect of practice variation on resource utilization in infants hospitalized for viral lower respiratory illness. Pediatrics. 2001;108(4):851-5.

8. Anil AB, Anil M, Saglam AB, Cetin N, Bal A, Aksu N. High volume normal saline alone is as effective as nebulized salbutamol-normal saline, epinephrine-normal saline, and $3 \%$ saline in mild bronchiolitis. Pediatr Pulmonol. 2010;45:41-7.

9. Wainwright C. Acute Viral Bronchiolitis in children- a very common condition with few therapeutic options. Paediatr Respir Rev. 2010;11:39-45. 
10. Zhang L, Mendoza-Sassi RA, Wainwright C, Klassen TP. Nebulised hypertonic saline solution for acute bronchiolitis in infants. Cochrane Database of Syst Rev. 2013, Issue 7. Art. No.: CD006458. doi:10.1002/14651858.CD006458.pub3.

11. Al-Ansari K, Sakran M, Davidson BL, El Sayyed R, Mahjoub H, Ibrahim K. Nebulised 5 or 3 or $0.9 \%$ saline for treating acute bronchiolitis in infants. J Pediatr. 2010;157:630-4.

12. Mandelberg A, Amirav I. Hypertonic saline or high volume normal saline for viral bronchiolitis: mechanisms and rationale. Pediatr Pulmonol. 2010;45:36-40.

13. Giudice M, Saitta F, Leonardi S. Effectiveness of nebulized hypertonic saline and epinephrine in hospitalized infants with bronchiolitis. Int I Immunopathol Pharmacol. 2012;25(2):485-91.

14. Kuzik BA, Al Qadhi SA, Kent S. Nebulised hypertonic saline in the treatment of viral bronchiolitis 1 in infants. J Pediatr. 2007;151:266-70.

15. Luo Z, Fu Z, Liu E. A randomized controlled trial of nebulised hypertonic saline treatment in hospitalized children with moderate to severe viral bronchiolitis. J Clin Microbiol Inf. 2011;17(12):1829-33.

16. Luo Z, Liu E, Luo J, Li S, Zeng F, Yang X, et al. Nebulized hypertonic saline/ salbutamol solution treatment in hospitalized children with mild to moderate bronchiolitis. Pediatr Int. 2010;52(2):199-202.

17. Mandelberg A, Tal G, Witzling M, Someck E, Houri S, Balin A, et al. Nebulised $3 \%$ hypertonic saline solution treatment for hospitalized infants with bronchiolitis. Chest. 2003;123:483-7.

18. Sarrell EM, Tal G, Witzling M, Someck E, Houri S, Cohen HA, et al. Nebulised $3 \%$ hypertonic saline solution for treatment of ambulatory children with viral bronchiolitis decreases symptoms. Chest. 2002;122:2015-20.

19. Tal G, Cesar K, Oron A. Hypertonic saline/ epinephrine treatment in hospitalized infants with viral bronchiolitis reduces hospitalization stay: 2 years experience. IMAJ. 2006:8:169-73.

20. Ipek IO, Yalchin EU, Sezer RG, Bozaykut A. The efficacy of nebulized salbutamol, hypertonic saline and salbutamol/hypertonic saline combination in moderate bronchiolitis. Pulm Pharmacol Ther. 2011;24(6):633-7.

21. Grewal S, Ali S, McConnell DW, Vandermeer B, Klassen TP. A randomized trial of nebulised $3 \%$ hypertonic saline with epinephrine in the treatment of acute bronchiolitis in the emergency department. Arch Pediatr Adolesc Med. 2009;163(11):1007-12.

22. Florin TA, Shaw KN, Kittick M, Yaskscoe S, Zorc JJ. Nebulized hypertonic saline for bronchiolitis in the emergency department: a randomized clinical trial. 1. JAMA Pediatr. 2014;168(7):664-702.

23. Teunissen J, Hochs AH, Vaessen-Verberne A, Boehmer AL, Smeets CC, Brackel $\mathrm{H}$, et al. The effect of 3 and $6 \%$ hypertonic saline in viral bronchiolitis: a randomised controlled trial. Eur Respir J. 2014;44(4):913-21.

24. Wu S, Baker C, Lang ME. Nebulized hypertonic saline for bronchiolitis: a randomized controlled trial. JAMA Pediatr. 2014;168(7):657-63.

25. Jacobs J, Foster M, Wan J, Pershad J. $7 \%$ hypertonic saline in acute bronchiolitis: a randomized controlled trial. Pediatrics. 2014;133:e8.

26. Wang EE, Milner R, Allen U, Maj H. Bronchodilators for treatment of mild bronchiolitis: a factorial randomised trial. Arch Dis Child. 1992;67:289-93.

27. Subcommittee on Diagnosis and Management of Bronchiolitis. Diagnosis and management of bronchiolitis. Pediatrics. 2006;118:1774-93.

28. Saghaei M. Random allocation software for parallel group randomised trials. BMC Med Res Methodol. 2004:4:26.

29. Schultz KF, Altman DG, Moher D. CONSORT 2010 Statement: updated guidelines for reporting parallel group randomized trials. BMJ. 2010;340:c332

30. Ralston S, Hill V, Martinez M. Nebulised hypertonic saline without adjunctive bronchodilators for children with bronchiolitis. Pediatrics. 2010;126:e520-5.

\section{Submit your next manuscript to BioMed Central and take full advantage of:}

- Convenient online submission

- Thorough peer review

- No space constraints or color figure charges

- Immediate publication on acceptance

- Inclusion in PubMed, CAS, Scopus and Google Scholar

- Research which is freely available for redistribution

Submit your manuscript at www.biomedcentral.com/submit 